\title{
Associations Between Health Education, Hygiene Facilities, Handwashing Knowledge and Practice Related to Diarrheal Disease Prevention among Schoolchildren after Typhoid Outbreak in Rumphi District, Malawi: A Cross Sectional Survey
}

\author{
BalwaniChingatichifwe Mbakaya ${ }^{1 *}$, Wai HangStephen Kwok ${ }^{2}$ and Letcher Mwenegamba Munyenyembe ${ }^{3}$ \\ ${ }^{1}$ St John's College of Nursing \& Midwifery, Malawi, Africa \\ ${ }^{2}$ The Hong Kong Polytechnic University, Hong Kong \\ ${ }^{3}$ Ministry of Health, Rumphi District Hospital, Malawi, Africa
}

*Corresponding author: Balwani Chingatichifwe Mbakaya, St John’s College of Nursing \& Midwifery, Malawi, Africa

\begin{abstract}
ARTICLE INFO
Received: March 28, 2019

Published: April 04, 2019

Citation: Balwani C Mbakaya*, Kwok W Hang Stephen, L Mwenegamba Munyenyembe. Associations Between Health Education, Hygiene Facilities, Handwashing Knowledge and Practice Related to Diarrheal Disease Prevention among Schoolchildren after Typhoid Outbreak in Rumphi District, Malawi: A Cross Sectional Survey. Biomed J Sci \& Tech Res 16(5)-2019. BJSTR. MS.ID.002908.
\end{abstract}

ABSTRACT

Background: Typhoid fever is a global health challenge and burden. Contamination of water and hands were found associated with higher risk of contracting typhoid. Schoolchildren should be a target population in disease prevention. Experimental studies showed that water treatment and hand hygiene education were effective in reducing illness and sick leave rate. The study aim is to investigate the associations between health education, hygiene facilities, handwashing knowledge and practice related to diarrheal disease prevention among school students after typhoid outbreak in Rumphi District, Malawi.

Methods: The study design was cross sectional survey. Students studying grade 7-8 in schools within catchment area for Kaziwiziwi Coal Mine in which health education about diarrheal disease (including typhoid) prevention in 2012 had taken place were recruited. A research assistant delivered the self-administered questionnaires to students recruited. The data collection was done within the Nov-Dec 2017 in schools recruited. IBM SPSS 21 was used for data analysis. Mixed model was adopted to fit data.

Results: The respondents were grade $7(n=131)$ and grade $8(n=105)$ students from 6 schools. There were $47 \%$ male. Without education received from health personnel, education received from other people was associated with a lower knowledge score (B $=-.233,95 \% \mathrm{CI}[-.464,-.001], \mathrm{p}=.049)$. The use of well, river and pipe as water source at school were associated with a better handwashing practice. Handwashing knowledge score was significantly associated with better handwashing practice score $(\mathrm{B}=0.703$, $95 \%$ CI $[0.378,1.029], \mathrm{t}=4.258, \mathrm{p}<.001)$.

Conclusion: The hypotheses of significant effect of reception of education about diarrheal disease (including typhoid) prevention on the handwashing knowledge, as well as significant effect of hygiene facilities and handwashing knowledge on handwashing practice were supported. Future studies should obtain more relevant information of target population and collect data pre and post intervention. 


\section{Introduction}

\section{Prominence of Typhoid Fever}

Typhoid fever is a global health challenge and burden. Crump, Luby [1] estimated that morbidity and mortality of typhoid fever were more than 21,650,000 and 216,000 respectively. High incidence of typhoid fever ( $>100 / 100,000$ cases per year) were estimated to prevail in Central Asia and South-East Asia [1]. Ochiai, Acosta [2] conducted a surveillance of typhoid fever in China, India, Indonesia, Pakistan and Vietnam between 2001 and 2004. The incidence of typhoid fever $\geq 3$ days for those age $>0$ and 5-15 were $108 / 100,000$ and $171 / 100,000$ respectively. The incidence of contracting Salmonella Typhi for fever cases aged > 0 and 5-15 were $2.2 \%$ and $2.4 \%$ respectively. Pakistan, India, and Bangladesh were the three countries in the world that together account for about $85 \%$ of the world's cases of typhoid fever identified [3]. The Middle East, North East Asia, Latin America, Caribbean and Africa were regarded as regions of medium incidence of typhoid fever (10-100/100,000 cases per year) [1]. In Africa, incidence of typhoid fever of $50 / 100,000$ cases were reported in 1994 [4]. However, the figure may not reflect undiagnosed cases. There were limitations on the study of incidence and burden of typhoid fever in Africa due to few laboratories to carry out clinical bacteriology to perform blood culture, and inadequate cheap reliable rapid laboratory diagnostic tools [5].

\section{Risk Factor of Typhoid}

Consumption of water contaminated with Salmonella Typhi and social gathering were found associated with a higher risk of contracting typhoid. Farooqui, Khan [6] conducted a cohort study of typhoid fever cases $(n=100)$ with temperature $>38^{\circ} \mathrm{C}$ since the onset of outbreak, abdominal discomfort, diarrhoea, vomiting and weakness in Karachi, Pakistan in 2004. Salmonella enterica serovar Typhi was found in $65 \%$ and $100 \%$ of the household and well water samples in the cases' living area. Salmonella Typhi was also found in $22 \%$ of clinical stool samples. Muti, Gombe [7] conducted a casecontrol study of suspected cases $(n=115)$ and their neighbour as controls $(n=115)$ in Dzivaresekwa Suburb of Harare City, Zimbabwe between October and December 2011. Social gathering (OR = 11.3, 95\% CI [4.3-29.95]), drinking well water (adjusted OR $=5.8,95 \%$ CI [1.90-17.78]) and sewer pipe burst at home (adjusted $\mathrm{OR}=1.20$, 95\% CI [1.10-2.19]) were associated with higher risk of contracting typhoid. Salmonella Typhi was found in $21 \%$ of stool, urine or blood samples of cases. Contamination of water and hands were found associated with higher risk of contracting typhoid. Anand and Ramakrishnan [8] conducted a retrospective cohort study of Indian in a village with typhoid outbreak in Thar Desert of Rajasthan in May-July 2007. The incidence of typhoid fever for those aged $>0$ and $10-14$ were $10 \%$ and $28 \%$ respectively. Drinking water from government tanks was associated with higher risk of contracting typhoid (RR $=11.1,95 \%$ CI [3.7-33]), while faecal material was found in $67 \%$ of water sample from government tanks. Widal agglutination tests were found positive in $61 \%$ of serum samples. Mbakaya, Mukora-Mutseyekwa [9] conducted a case-control study of cases suffering from typhoid $(n=50)$ and controls $(n=50)$ in Kaziwiziwi coal mine in Rumphi District, Malawi between May and June, 2012. Untreated water from a nearby river (OR $=2.7,95 \%$
CI $[1.2,6.3], \mathrm{p}=0.0176)$ and a lack of handwashing facility after toilet $(\mathrm{OR}=2.6,95 \% \mathrm{CI}[1.1,6.1], \mathrm{p}=0.0236)$ were associated with higher risk of contracting typhoid.

\section{Population at Risk}

Schoolchildren should be a target population in disease prevention because they are one of the most vulnerable groups in the community. Results from literature indicated that typhoid is wide spread across much of the continent, such that in Egypt, Kenya and South Africa, typhoid has been described as a major health problem in schoolchildren [5]. Students clustered in the same setting during school days, which increase the chance of disease transmission. Therefore, school is one of the target settings of infection control in the public health agenda.

\section{Intervention for Infection Control}

Experimental studies showed that water treatment and hand hygiene education were effective in reducing illness and sick leave rate. Talaat, Afifi [10] conducted an RCT of grades 1-3 ( $\mathrm{n}=44451)$ in elementary schools $(n=60)$ in Cairo, Egypt between February and May, 2008. Hand hygiene campaign (wash hands twice each day, receiving health messages) was associated with lower odds of absenteeism due to influenza-like illness (OR $=0.68$ ), diarrhea (OR $=0.55$ ) and conjunctivitis (OR $=0.49)$. Patel, Harris [11] conducted an experimental study of grades 4-8 $(n=327)$ among ordinary schools $(\mathrm{n}=42$ ) in Nyanza province, Kenya between 2007 and 2009. School-based hygiene and water treatment programs was associated with lower estimated median of any kinds of illness (diarrhea, cough/difficulty breathing, rhinorrhea/coryza, or fever) $(\mathrm{EDM}=-3,95 \% \mathrm{CI}[-4,-1])$ and acute respiratory illness (fever and cough) (EDM $=-2,95 \%[-3,-1])$ in intervention group.

\section{Typhoid Outbreak Control in Malawi}

A typhoid outbreak occurred from $21^{\text {st }}$ May to $15^{\text {th }}$ June in 2012 at Kaziwiziwi coal mine and the surrounding villages situated in the eastern and mountainous part of the Rumphi District, Malawi. It was declared by the Malawi Ministry of Health $(\mathrm{MoH})$ after lab confirmation. An outbreak investigation was launched and infection control was implemented. During the period, residents of surrounding villages and schoolchildren were given treatment, prophylaxis and health education on how to prevent typhoid and diarrheal related infections such as endemic malaria, irregular events of diarrhoea and respiratory tract infections which were common in the area throughout the year [12]. Intervention for the public included components such as health education on typhoid fever to raise awareness among public; distributing chlorine for water treatment for those who were affected; construction of pit latrines since there were few and some homes did not have pit latrine; constructing hand washing facility near toilet and in homes; banning the sale of locally prepared sweet beer; and use of treated water as people were using untreated water from a river. Key messages of health education in schools in the catchment area for Kaziwiziwi coal mine were using potable drinking water (treated with sodium hypochlorite, commonly known as chlorine); using pit latrines; washing hands with soap at the 5 critical times such as after using latrine and before food preparation; and consumption of thoroughly cooked foods. There was no follow up, however, on 
the effects of the interventions on hand hygiene knowledge and practice among the schoolchildren. Results from the follow up may inform improvement, development and generalisability of interventions for children and adolescents, whose incidence of typhoid was higher than general public according to literature.

\section{Aim}

The study aim was to investigate the associations between health education, hygiene facilities, handwashing knowledge and practice related to diarrheal disease prevention among schoolchildren after typhoid outbreak in Rumphi District, Malawi.

\section{Objectives}

The study objectives are to investigate

a) The location of students' school (outside/inside catchment area for Kaziwiziwi coal mine) at the time of typhoid fever outbreak (within academic year of 2012-13) and at the time of data collection (within Nov-Dec 2017).

b) The reception of education about diarrheal disease (including typhoid) prevention among schoolchildren at the time of typhoid fever outbreak (within academic year of 201213) and within 2 years preceding data collection (within NovDec 2015- Nov-Dec 2017).

c) The hygiene facilities, handwashing knowledge and practice among schoolchildren at the time of data collection (within Nov-Dec 2017).

\section{Hypothesis}

The alternative hypotheses are that

a) The school location by time interaction has a significant effect on the reception of education about diarrheal disease (including typhoid) prevention.

b) The reception of education about diarrheal disease (including typhoid) prevention has a significant effect on the handwashing knowledge.

c) Hygiene facilities has significant effect on handwashing practice.

d) Handwashing knowledge has significant effect on handwashing practice.

\section{Methods}

\section{Design}

The study design was cross sectional survey.

\section{Ethical Considerations}

Ethical approval was obtained from the National Health Sciences Research Committee, Malawi (Approval number: 1805). Clearance was obtained from the District Education Management Office (DEMO), Malawi and the headmasters of the schools. Participants were informed of the study nature, purpose and objectives. Participants were informed that participation is voluntary and they can freely withdraw without penalty. Written informed consents were obtained from participants' parents or guardians prior to data collection. Informed consents were also obtained from students. Privacy, anonymity and confidentiality were ensured. Real name of student was not required and students were identified with code. Access of data was restricted to primary researcher and research assistants.

\section{Sampling}

A research assistant recruited schools and their students by using convenience sampling method. The recruitment period was within the Nov-Dec 2017 in Rumphi District, Malawi. Between the time of typhoid fever outbreak (within academic year of 2012-13) and the time of data collection (within Nov-Dec 2017), school of students may change, either located outside or inside the catchment area for Kaziwiziwi coal mine in the Rumphi District.

\section{Inclusion}

The inclusion criteria at school level were schools within catchment area for Kaziwiziwi Coal Mine, and received health education about diarrheal disease (including typhoid) prevention in 2012. The inclusion criteria at student level were students studying grade 7-8, and without physical, mental or learning disability. These are students who were supposed to be in junior classes during the typhoid outbreak in 2012/2013 academic year.

\section{Assessment}

A research assistant delivered the self-administered questionnaires to students recruited. The data collection was done within the Nov-Dec 2017 in schools recruited. Questionnaires were completed in school setting for the convenience of mass delivery and collection of questionnaires.

\section{Instrument}

The questionnaire used was semi structured. Students were required to fill in the blanks for items related to demographic characteristics such as school, grade, age, gender, religion, as well as items related to perceived activities for diarrheal disease (including typhoid) prevention and handwashing steps/technique. Dichotomous and Likert scales were used to assess items related to domains of health education, hygiene facilities, handwashing knowledge and practice. Knowledge score and practice score were sum of item scores within a domain respectively.

\section{Translation}

The primary researcher and research assistants developed and translated the questionnaire. The target population was Malawi students therefore the questionnaire was prepared in local language and an English version for international readers. The English version was translated into Tumbuka by the primary researcher. Then, the Tumbuka version was translated back into English by a research assistant. Both English versions were compared by another research assistant who found no major discrepancy between the versions.

\section{Analysis}

IBM SPSS 21 was used for data analysis. All of the items have missing $<7.2 \%$. There were $87.5 \%$ of items with missing $<3 \%$. No imputation was done for missing $<10 \%$. The significance level was 
set at .05. Age of respondents was analysed with one way ANOVA. Gender, grade and religion between schools were analysed with Pearson's chi square test.

\section{Model}

Mixed model was adopted to fit data. The calculation of df was based on residual method. Robust covariance estimator was used. Reception of education about diarrheal disease (including typhoid) prevention from health personnel was a dichotomous variable. Binomial distribution and logit link function were specified. The fixed effects were academic year, school location, and their interaction. The covariance type of repeated measures was specified as first order autoregressive. Histogram of Knowledge score was checked, the score roughly followed a normal distribution. Normal distribution and identity link function were specified. The fixed effects were reception of education about diarrheal disease (including typhoid) prevention from health personnel (2012-13) (HP1), health personnel (Nov-Dec 2015- Nov-Dec 2017)(HP2), other people (Nov-Dec 2015- Nov-Dec 2017)(OP2) and their interaction. The covariance type of random intercepts among schools was specified as diagonal.

Histogram of Practice score was checked, the score followed a normal distribution. Normal distribution and identity link function were specified. The fixed effects were Well as source of water at home, Well as source of water at school, River as source of water at home, River as source of water at school, Pipe as source of water at home, Pipe as source of water at school, Borehole as source of water at home, Borehole as source of water at school, Handwashing facility at home, Handwashing facility at school, Knowledge score. There were $100 \%$ and $99.2 \%$ of the respondents reported having latrine at home and at school respectively. Therefore, latrine was not included as fixed effect of Practice score. The covariance type of random intercepts among schools was specified as diagonal.

\section{Assumption Check}

Boxplots of Pearson residuals between schools, Q-Q plot of Pearson residuals, scatterplot of Pearson residuals against predicted values, and LOESS curve calculated with Epanechnikov's kernel fitting through $50 \%$ of points on the scatterplot were checked. There were no significant violations of assumptions of independence of observations, normality, homoscedasticity and linearity.

\section{Results}

The mean age of respondents in Total was 14.25 (95\% CI $[14.02,14.48], \mathrm{SD}=1.795$, range $=10-20)$ (Table 1$)$. There was no heterogeneity of variance (Levene $(4,234)=0.964, p=0.428$ ) (Table $2)$. There was significant difference in age of respondents between schools $(F(4,234)=3.763, p=0.005)$, supported by robust test of equality of means such as Welch $(4,99.385)=3.934(p=0.005)$ and Brown-Forsythe $(4,211.118)=3.902(p=0.004)$. There were significant differences in Grade (Pearson $\chi 2(4)=28.392, p<.001)$ and Religion (Pearson $\chi 2(12)=51.784, p<.001)$ between schools (Table 3). However, there were 10 cells (50.0\%) having expected count less than 5 in the crosstab of religion between schools. There was significant difference in school location (Pearson $\chi 2$ (1) = $100.298, \mathrm{p}<.001$ ) between academic years (Table 4).

Table 1: Descriptive statistics of age of respondents (Nov-Dec 2017).

\begin{tabular}{|c|c|c|c|c|c|c|c|c|}
\hline \multirow[t]{2}{*}{ School } & \multirow[t]{2}{*}{$N$} & \multirow[t]{2}{*}{ Mean } & \multirow[t]{2}{*}{$S D$} & \multirow[t]{2}{*}{$S E$} & \multicolumn{2}{|c|}{ 95\% CI for Mean } & \multirow[t]{2}{*}{ Minimum } & \multirow[t]{2}{*}{ Maximum } \\
\hline & & & & & Lower Bound & Upper Bound & & \\
\hline Dongo & 26 & 13.58 & 1.501 & 0.294 & 12.97 & 14.18 & 11 & 17 \\
\hline $\begin{array}{l}\text { Rumphi- } \\
\text { Phoka }\end{array}$ & 54 & 14.81 & 1.738 & 0.237 & 14.34 & 15.29 & 10 & 18 \\
\hline Junju & 63 & 14.52 & 1.703 & 0.214 & 14.1 & 14.95 & 12 & 20 \\
\hline Thundu & 60 & 13.8 & 1.903 & 0.246 & 13.31 & 14.29 & 10 & 18 \\
\hline Kaziwiziwi & 36 & 14.14 & 1.775 & 0.296 & 13.54 & 14.74 & 11 & 18 \\
\hline Total & 239 & 14.25 & 1.795 & 0.116 & 14.02 & 14.48 & 10 & 20 \\
\hline
\end{tabular}

Table 2: Inferential statistics of age of respondents (Nov-Dec 2017).

\begin{tabular}{|c|c|c|c|c|}
\hline Test & Statistic & df1 & df2 & p \\
\hline Levene & 0.964 & 4 & 234 & 0.428 \\
\hline$F$ & 3.763 & 4 & 234 & 0.005 \\
\hline Welch $^{\mathrm{a}}$ & 3.934 & 4 & 99.385 & 0.005 \\
\hline Brown-Forsythe $^{\mathrm{a}}$ & 3.902 & 4 & 211.118 & 0.004 \\
\hline
\end{tabular}

Note: a Asymptotically F distributed.

Table 3: Crosstab of demographic characteristics between schools (Nov-Dec 2017).

\begin{tabular}{|c|c|c|c|c|c|c|c|c|c|}
\hline & \multicolumn{3}{|c|}{ School } & Total & & \\
\hline & Dongo & $\begin{array}{c}\text { Rumphi- } \\
\text { Phoka }\end{array}$ & Junju & Thundu & Kaziwiziwi & & Pearson $\chi \mathbf{2}$ & $\begin{array}{c}\text { Asymp. } \boldsymbol{p} \\
\text { (2-sided) }\end{array}$ \\
\hline Gender & & & & & & & & \\
\hline Male & 13 & 28 & 20 & 25 & 18 & 104 & 5.204 & 4 & 0.267 \\
\hline Female & 13 & 20 & 34 & 33 & 18 & 118 & & \\
\hline
\end{tabular}




\begin{tabular}{|c|c|c|c|c|c|c|c|c|}
\hline Total & 26 & 48 & 54 & 58 & 36 & 222 & & \\
\hline Grade & & & & & & & & \\
\hline Grade 7 & 26 & 27 & 30 & 35 & 13 & 131 & 28.392 & 4 \\
\hline Grade 8 & 0 & 26 & 32 & 24 & 23 & 105 & $<.001$ \\
\hline Total & 26 & 53 & 62 & 59 & 36 & 236 & & \\
\hline Religion & & 0 & 3 & 1 & 0 & 4 & 51.784 a & 12 \\
\hline $\begin{array}{c}\text { Roman } \\
\text { Catholic }\end{array}$ & 0 & 11 & 28 & 47 & 16 & 111 & & $<.001$ \\
\hline Protestant & 9 & 0 & 1 & 1 & 0 & 2 & & \\
\hline $\begin{array}{c}\text { Seventh-day } \\
\text { Adventist }\end{array}$ & 0 & 43 & 31 & 11 & 20 & 122 & & \\
\hline $\begin{array}{c}\text { Other } \\
\text { Total }\end{array}$ & 17 & 54 & 63 & 60 & 36 & 239 & & \\
\hline
\end{tabular}

Note: ${ }^{a} 10$ cells $(50.0 \%)$ have expected count less than 5 . The minimum expected count is 22 .

Table 4: Crosstab of school locations between academic years (2012-13, Nov-Dec 2017).

\begin{tabular}{|c|c|c|c|c|c|c|}
\hline & \multicolumn{2}{|c|}{ Academic year } & Total & Pearson $\chi \mathbf{2}$ & df & $\begin{array}{c}\text { Asymp. p } \\
\text { (2-sided) }\end{array}$ \\
\hline School location & $\mathbf{2 0 1 2 - 1 3}$ Nov-Dec 2017 & & & \\
\hline $\begin{array}{c}\text { Outside catchment } \\
\text { area }\end{array}$ & 81 & 0 & 81 & 100.298 & 1 & $<.001$ \\
\hline $\begin{array}{c}\text { Inside catchment } \\
\text { area }^{a}\end{array}$ & 152 & 239 & 391 & & & \\
\hline Total & 233 & 239 & 472 & & & \\
\hline
\end{tabular}

Note: afor Kaziwiziwi coal mine.

The fixed effect of Academic year (2012-13/ Nov-Dec 2015Nov-Dec 2017) $(\mathrm{F}(1,446)=39.397, \mathrm{p}<.001)$ was significant while controlling for other fixed effects (Table 5). Compared with NovDec 2015- Nov-Dec 2017, 2012-13 (OR = 0.298, 95\% CI [0.204, $0.435], \mathrm{p}<.001$ ) was significantly associated with lower odds of reception of education about diarrheal disease (including typhoid) prevention from health personnel (Table 6). The fixed effect of OP2
$(\mathrm{F}(1,213)=10.621, \mathrm{p}=0.001)$ was significant while controlling for other fixed effects (Table 7). [HP1 = No] by [HP2 = No] by [OP2 $=$ Yes] interaction $(\mathrm{B}=-.233,95 \%$ CI $[-.464,-.001], \mathrm{p}=.049)$ was significantly associated with lower (worse) Knowledge score (Table 8). The random effect of intercept ( $\sigma 2=.012,95 \%$ CI [.002, .069], Z $=1.107, \mathrm{p}=.268$ ) was insignificant.

Table 5: Fixed Effects a on reception of education.

\begin{tabular}{|c|c|c|c|c|}
\hline Source & $\mathbf{F}$ & $d f 1$ & $d f 2$ & $p$ \\
\hline Corrected Model & 26 & 2 & 446 & $<.001$ \\
\hline $\begin{array}{c}\text { Academic year (2012-13/ Nov-Dec 2015- Nov- } \\
\text { Dec 2017) }\end{array}$ & 39.397 & 1 & 446 & $<.001$ \\
\hline $\begin{array}{l}\text { School location (Outside/ Inside catchment } \\
\text { area for Kaziwiziwi coal mine) }\end{array}$ & 1.242 & 1 & 446 & 0.266 \\
\hline School location by Academic year & . & 0 & . & . \\
\hline
\end{tabular}

Note: Probability distribution: Binomial

Link function: $\log$

a) Target: About diarrheal disease (including typhoid) prevention from health personnel

Table 6: Fixed Coefficients a on reception of education.

\begin{tabular}{|c|c|c|c|c|c|c|c|c|c|}
\hline \multirow{2}{*}{ Model Term } & \multirow{2}{*}{ Coefficient } & \multirow{2}{*}{ SE } & \multirow{2}{*}{ t } & \multirow{2}{*}{$\mathbf{p}$} & \multicolumn{2}{|c|}{$95 \% \mathrm{CI}$} & \multirow{2}{*}{ OR } & \multicolumn{2}{|c|}{$95 \%$ CI for OR } \\
\hline & & & & & Lower & Upper & & Lower & Upper \\
\hline Intercept & 0.539 & 0.1377 & 3.914 & $<.001$ & 0.268 & 0.81 & 1.714 & 1.308 & 2.247 \\
\hline $2012-13$ & -1.211 & 0.1929 & -6.277 & $<.001$ & -1.59 & -0.832 & 0.298 & 0.204 & 0.435 \\
\hline $\begin{array}{c}\text { Nov-Dec 2015- Nov-Dec } \\
2017\end{array}$ & $0^{\mathrm{b}}$ & . & . & . & . & $\cdot$ & . & . & . \\
\hline
\end{tabular}




\begin{tabular}{|c|c|c|c|c|c|c|c|c|c|}
\hline Outside & 0.285 & 0.2559 & 1.114 & 0.266 & -0.218 & 0.788 & 1.33 & 0.804 & 2.199 \\
\hline Inside & $0^{\mathrm{b}}$ & . & . & . & . & . & . & . & . \\
\hline [Outside] by [2012-13] & $0^{\mathrm{b}}$ & . & . & . & . & . & . & . & . \\
\hline [Inside] by [2012-13] & $0^{\mathrm{b}}$ & . & . & . & . & . & . & . & . \\
\hline $\begin{array}{c}\text { [Inside] by [2015- } \\
2017]\end{array}$ & $0^{\mathrm{b}}$ & . & . & . & . & . & . & . & . \\
\hline
\end{tabular}

Note: Probability distribution: Binomial

Link function: $\log$

a) Target: About diarrheal disease (including typhoid) prevention from health personnel

b) This coefficient is set to zero because it is redundant.

Table 7: Fixed Effects a on Knowledge score.

\begin{tabular}{|c|c|c|c|c|}
\hline Source & F & $\boldsymbol{d f 1}$ & $\boldsymbol{d f 2}$ & $\boldsymbol{p}$ \\
\hline Corrected Model & 4.084 & 4 & 213 & 0.003 \\
\hline HP1 & 0.733 & 1 & 213 & 0.393 \\
\hline HP2 & 0.046 & 1 & 213 & 0.831 \\
\hline OP2 & 10.621 & 1 & 213 & 0.001 \\
\hline HP1 by HP2 by OP2 & 1.959 & 2 & 213 & 0.144 \\
\hline
\end{tabular}

Note: Probability distribution: Normal

Link function: Identity

a) Target: Knowledge score

Table 8: Fixed Coefficients a on Knowledge score.

\begin{tabular}{|c|c|c|c|c|c|c|}
\hline \multirow{2}{*}{ Model Term } & \multirow{2}{*}{ Coefficient } & \multirow{2}{*}{$S E$} & \multirow{2}{*}{$t$} & \multirow{2}{*}{$p$} & \multicolumn{2}{|c|}{$95 \% \mathrm{CI}$} \\
\hline & & & & & Lower & Upper \\
\hline Intercept & 1.1 & 0.1111 & 9.9 & $<.001$ & 0.881 & 1.319 \\
\hline HP1 = No & 0.075 & 0.0864 & 0.867 & 0.387 & -0.095 & 0.245 \\
\hline HP1 = Yes & $0^{\mathrm{b}}$ & . & . & . & . & . \\
\hline HP2 $=$ No & 0.041 & 0.0735 & 0.56 & 0.576 & -0.104 & 0.186 \\
\hline HP2 = Yes & $0^{\mathrm{b}}$ & . & . & . & . & . \\
\hline $\mathrm{OP} 2=\mathrm{No}$ & 0.02 & 0.0487 & 0.418 & 0.676 & -0.076 & 0.116 \\
\hline $\mathrm{OP} 2=\mathrm{Yes}$ & $0^{\mathrm{b}}$ & . & . & . & . & . \\
\hline$[\mathrm{HP} 1=\mathrm{No}]$ by $[\mathrm{HP} 2=\mathrm{No}]$ by $[\mathrm{OP} 2=\mathrm{No}]$ & -0.126 & 0.0849 & -1.487 & 0.138 & -0.294 & 0.041 \\
\hline$[\mathrm{HP} 1=\mathrm{No}]$ by $[\mathrm{HP} 2=\mathrm{No}]$ by $[\mathrm{OP} 2=\mathrm{Yes}]$ & -0.233 & 0.1176 & -1.978 & 0.049 & -0.464 & -0.001 \\
\hline$[\mathrm{HP} 1=\mathrm{No}]$ by $[\mathrm{HP} 2=\mathrm{Yes}]$ by $[\mathrm{OP} 2=\mathrm{No}]$ & $0^{\mathrm{b}}$ & . & . & . & . & . \\
\hline$[\mathrm{HP} 1=\mathrm{Yes}]$ by $[\mathrm{HP} 2=\mathrm{No}]$ by $[\mathrm{OP} 2=\mathrm{No}]$ & $0^{\mathrm{b}}$ & . & . & . & . & . \\
\hline$[\mathrm{HP} 1=\mathrm{Yes}]$ by $[\mathrm{HP} 2=\mathrm{No}]$ by $[\mathrm{OP} 2=\mathrm{Yes}]$ & $0^{\mathrm{b}}$ & . & . & . & . & . \\
\hline$[\mathrm{HP} 1=\mathrm{Yes}]$ by $[\mathrm{HP} 2=\mathrm{Yes}]$ by $[\mathrm{OP} 2=\mathrm{No}]$ & $0^{\mathrm{b}}$ & . & . & . & . & . \\
\hline
\end{tabular}

Note: Probability distribution: Normal

Link function: Identity

a) Target: Knowledge score

b) This coefficient is set to zero because it is redundant.

The fixed effects of Well as source of water at home (F (1, 210) $=4.533, \mathrm{p}=0.034)$, Well as source of water at school $(\mathrm{F}(1,210)$

$=4.909, \mathrm{p}=0.028)$, River as source of water at home $(\mathrm{F}(1,210)$

were significant while controlling for other fixed effects (Table 9). Compared with Well and River as source of water at home=Yes, Well as source of water at home $=$ No $(B=1.225,95 \% C I[0.091,2.359], t$

$=8.334, \mathrm{p}=0.004)$, River as source of water at school $(\mathrm{F}(1,210)$ $=2.129, \mathrm{p}=0.034)$ and River as source of water at home $=$ No $(\mathrm{B}=$

$=64.384, \mathrm{p}<.001)$, Pipe as source of water at school $(\mathrm{F}(1,210)=1.162,95 \% \mathrm{CI}[0.368,1.955], t=2.887, \mathrm{p}=0.004)$ were significantly 4.255, $\mathrm{p}=0.04)$, Knowledge score $(\mathrm{F}(1,210)=18.132, \mathrm{p}<.001) \quad$ associated with higher (better) Practice score (Table 10). 
Table 9: Fixed Effects a on Practice score.

\begin{tabular}{|c|c|c|c|c|}
\hline Source & $\mathbf{F}$ & $d f 1$ & $d f 2$ & $p$ \\
\hline Corrected Model & 26.066 & 4 & 210 & $<.001$ \\
\hline Well as source of water at home & 4.533 & 1 & 210 & 0.034 \\
\hline Well as source of water at school & 4.909 & 1 & 210 & 0.028 \\
\hline River as source of water at home & 8.334 & 1 & 210 & 0.004 \\
\hline River as source of water at school & 64.384 & 1 & 210 & $<.001$ \\
\hline Pipe as source of water at home & 1.352 & 1 & 210 & 0.246 \\
\hline Pipe as source of water at school & 4.255 & 1 & 210 & 0.04 \\
\hline Borehole as source of water at home & 0.396 & 1 & 210 & 0.53 \\
\hline Borehole as source of water at school & 2.308 & 1 & 210 & 0.13 \\
\hline Handwashing facility at home & 0.306 & 1 & 210 & 0.58 \\
\hline Handwashing facility at school & 0.577 & 1 & 210 & 0.448 \\
\hline Knowledge score & 18.132 & 1 & 210 & $<.001$ \\
\hline
\end{tabular}

Note: Probability distribution: Normal

Link function: Identity

a) Target: Practice score

Table 10: Fixed Coefficients a on Practice score.

\begin{tabular}{|c|c|c|c|c|c|c|}
\hline \multirow{2}{*}{ Model Term } & \multirow{2}{*}{ Coefficient } & \multirow{2}{*}{$S E$} & \multirow{2}{*}{$t$} & \multirow{2}{*}{$p$} & \multicolumn{2}{|c|}{$95 \% \mathrm{CI}$} \\
\hline & & & & & Lower & Upper \\
\hline Intercept & 3.488 & 1.7373 & 2.008 & 0.046 & 0.064 & 6.913 \\
\hline Well as source of water at home $=$ No & 1.225 & 0.5754 & 2.129 & 0.034 & 0.091 & 2.359 \\
\hline Well as source of water at home=Yes & $0^{\mathrm{b}}$ & . & . & . & . & . \\
\hline Well as source of water at school=No & -0.623 & 0.281 & -2.216 & 0.028 & -1.177 & -0.069 \\
\hline Well as source of water at school=Yes & $0^{\mathrm{b}}$ & . & . & . & . & . \\
\hline River as source of water at home=No & 1.162 & 0.4024 & 2.887 & 0.004 & 0.368 & 1.955 \\
\hline River as source of water at home=Yes & $0^{\mathrm{b}}$ & . & . & . & . & . \\
\hline River as source of water at school=No & -2.41 & 0.3004 & -8.024 & $<.001$ & -3.002 & -1.818 \\
\hline River as source of water at school=Yes & $0^{\mathrm{b}}$ & . & . & . & . & . \\
\hline Pipe as source of water at home $=$ No & 0.805 & 0.6924 & 1.163 & 0.246 & -0.56 & 2.17 \\
\hline Pipe as source of water at home=Yes & $0^{\mathrm{b}}$ & . & . & . & . & . \\
\hline Pipe as source of water at school=No & -1.096 & 0.5311 & -2.063 & 0.04 & -2.143 & -0.049 \\
\hline Pipe as source of water at school=Yes & $0^{\mathrm{b}}$ & . & . & . & . & . \\
\hline Borehole as source of water at home $=$ No & 0.393 & 0.6248 & 0.63 & 0.53 & -0.838 & 1.625 \\
\hline Borehole as source of water at home=Yes & $0^{\mathrm{b}}$ & . & . & . & . & . \\
\hline Borehole as source of water at school=No & -0.865 & 0.5695 & -1.519 & 0.13 & -1.988 & 0.257 \\
\hline Borehole as source of water at school=Yes & $0^{\mathrm{b}}$ & . & . & . & . & . \\
\hline Handwashing facility at home $=$ No & 0.35 & 0.6316 & 0.554 & 0.58 & -0.895 & 1.595 \\
\hline Handwashing facility at home=Yes & $0^{\mathrm{b}}$ & . & . & . & . & . \\
\hline Handwashing facility at school=No & 0.143 & 0.1883 & 0.76 & 0.448 & -0.228 & 0.514 \\
\hline Handwashing facility at school=Yes & $0^{\mathrm{b}}$ & . & . & . & . & . \\
\hline Knowledge score & 0.703 & 0.1652 & 4.258 & $<.001$ & 0.378 & 1.029 \\
\hline
\end{tabular}

Note: Probability distribution: Normal

Link function: Identity

a) Target: Practice score

b) This coefficient is set to zero because it is redundant. 
Compared with Well, River and Pipe as source of water at school=Yes, Well as source of water at school=No $(B=-0.623,95 \% \mathrm{CI}$ [-1.177, -0.069], $\mathrm{t}=-2.216, \mathrm{p}=0.028)$, River as source of water at school=No (B = -2.41, 95\%CI [-3.002, -1.818], $\mathrm{t}=-8.024, \mathrm{p}<.001$ ), Pipe as source of water at school=No (B = -1.096, 95\%CI $[-2.143$, $-0.049], \mathrm{t}=-2.063, \mathrm{p}=0.04$ ) were significantly associated with lower (worse) Practice score. Knowledge score (B $=0.703,95 \% \mathrm{CI}$ $[0.378,1.029], t=4.258, p<.001)$ was significantly associated with higher (better) Practice score. The random effect of intercept was redundant.

\section{Discussion}

The hypothesis of significant effect of school location by time interaction on the reception of education about diarrheal disease (including typhoid) prevention was not supported. According to the study results, the location of students' school across time did not have a significant effect on the reception of the education. On the other hand, compared with 2015-2017, 2012-13 academic year was significantly associated with $70 \%$ lower odds of reception of the education. Therefore, time has a significant effect on the reception of the education. There could be two reasons of the results. First, the school outside Kaziwiziwi catchment area might have had a chance to be exposed to hygiene education too after learning that there was an outbreak of typhoid in Kaziwiziwi. Second, there could have been a general education awareness on radio and other forms of media by government and other stakeholders on water, sanitation and hygiene (WASH) which is advocated by UNICEF Malawi in response to seasonal outbreak of diarrhoeal diseases in the country.

The hypothesis of significant effect of reception of education about diarrheal disease (including typhoid) prevention on the handwashing knowledge was supported. According to the study results, the fixed effect of the education from other people within 2015-2017 was significant. Therefore, the education from other people within 2015-2017 has a significant effect on handwashing knowledge. On the other hand, No education from health personnel in 2012-13 by no education from health personnel in 2015- 2017 by education received from other people in 2015- 2017 was significantly associated with a lower knowledge score by 0.23 . Therefore, under the situation of no education received from health personnel, education received from other people was associated with a lower knowledge score when compared with other combinations of situations. There may be two reasons of the results. First, the category of the other people was not specific. There may be a specific occupation such as teacher or relationship with the student such as mother who has a significant effect on students handwashing knowledge.

Second, without education from health personnel, even the education received from other people may not be effective in increasing students' handwashing knowledge. Health education should be delivered by qualified personnel. The findings of this study are similar to previous study in which the educational intervention offered by trained personnel significantly increased knowledge of students on prevention of infectious diseases [13]. Health workers are expert in health issues. As such, they are better positioned to provide hand hygiene education to primary school students. The hypothesis of significant effect of hygiene facilities on handwashing practice was supported. According to the study results, the well and river as source of water at home and school, pipe as source of water at school and handwashing knowledge score have significant effects on handwashing practice score. Compared with those using well and river as water source at home, those not using well and river as water source at home were significantly associated with higher (better) practice score. Therefore, the use of a well and river as water source at home was associated with a worse handwashing practice. Compared with those using well, river and pipe as water source at school, those not using well, river or pipe as water source at school were significantly associated with lower (worse) practice score. Therefore, the use of well, river and pipe as water source at school were associated with a better handwashing practice. Students who have readily sufficient water to use may have higher frequency of handwashing in different circumstances and therefore better handwashing practice.

It could be that the school setting provided a conducive environment for students to learn from each other and got motivated, hence practiced hand washing more regardless of the source of water. Unlike in the home setting where some children could be alone without observing other practice handwashing. Most parents get their income through farming and mining in Kawiziwi area hence could be out of home and busy most of the time. In school setting, teachers might have played a greater role in reinforcing the hand hygiene practice after the education was delivered in schools by health workers during the outbreak. The results of this study (at school) conquer with previous studies which found positive link between availability of resources and hand hygiene practice [11,14-16]. In situations where resources are not available, people do not prioritize hand hygiene $[17,18]$. Availability of resources is associated with better handwashing practice, because resources act as a motivation to practice hand hygiene.

However, there is a contraction with this study (at home) where the use of resources such as a well and river as water source at home was associated with a worse handwashing practice. The setting of the school and home could have played a greater role for the prevailing difference in this study. The hypothesis of significant effect of handwashing knowledge on handwashing practice was supported. Knowledge score was significantly associated with higher (better) Practice score by .70. Therefore, more handwashing knowledge was associated with a better handwashing practice. Health education influences self-efficacy by raising positive awareness, influencing their knowledge, attitude and practice/ behaviour on hand hygiene [19]. Communities in developing countries need to be encouraged to practice proper hand hygiene using the available resources while taking necessary caution to treat unsafe water sources with locally available treatment such as chlorine, Ultraviolet (UV) light, water guard in order to avoid crosscontamination.

\section{Limitations}

In this survey, there may be recall bias of students about the reception of education. At the time of data collection, students may forget the reception of education in 2012-13. Categories of certain variables were not specific such as the other people who delivered 
health education. Household income, assets and education level of individuals, as well as financial status, manpower and assets of schools had not been assessed. Their associations with target variables could not be tested.

\section{Recommendations}

In future studies, data should be collected for assessment and baseline reference before and after implementing intervention with planned follow up. Categories of nominal measurement should be as specific as possible. More relevant background information of respondents and schools should be obtained so as to generate a clearer picture of the sample at different levels and to estimate population parameters of target variables.

\section{Implications}

The study findings may be generalised to developing countries to prevent outbreaks of typhoid and other diarrheal diseases. The results are expected to have an influence on health policy, planned program services, health education and evidence based interventions on hygiene practices. It helps to inform the public health workers such as Environmental Health Officers, Health Surveillance Assistants (HAS), community health nurses and stakeholders in adopting evidence based interventions that work best in relevant circumstances to prevent infectious disease outbreaks in the community. This may in return improve the public health of the entire community, yet specifically benefit schoolchildren in terms of their health, school attendance and school performance, as well as contributes towards their growth and development.

\section{Conclusion}

The hypotheses of significant effect of reception of education about diarrheal disease (including typhoid) prevention on the handwashing knowledge, as well as significant effect of hygiene facilities and handwashing knowledge on handwashing practice were supported. Our findings amplify the global public health agenda which emphasizes the significance of health education to influence self-efficacy by raising positive awareness, influencing knowledge, attitude and practice/behaviour on hand hygiene. Future studies should obtain more relevant information of target population and collect data pre and post intervention.

\section{Funding}

No specific grant was received from any funding agency in support of this research.

\section{References}

1. Crump JA, Luby SP, Mintz ED (2004) The global burden of typhoid fever. Bull World Health Organ 82(5): 346-353.

2. Ochiai RL, Acosta CJ, Danovaro Holliday MC, Baiqing D, Bhattacharya SK, Agtini MD, et al. (2008) A study of typhoid fever in five Asian countries: disease burden and implications for controls. Bull World Health Organ 86(4): 260-268.

3. Maurice J (2012) A first step in bringing typhoid fever out of the closet. Lancet 379(9817): 699-700.

4. Singh B (2001) Symposium: Typhoid fever epidemiology. Journal, Indian Academy Clin Med 2(1-2): 11-12.

5. Steele D (2008) The importance of generating evidence on typhoid fever for implementing vaccination strategies. J Infection in Developing Countries 2(4): 250-252.

6. Farooqui A, Khan A, Kazmi SU (2009) Investigation of a community outbreak of typhoid fever associated with drinking water. BMC Public Health 9(476): 1-6.

7. Muti M, Gombe N, Tshimanga M, Takundwa L, Bangure D, Mungofa S, et al. (2014) Typhoid outbreak investigation in Dzivaresekwa, suburb of Harare City, Zimbabwe, 2011. Pan African Med J 18(309): 1-7.

8. Anand PK, Ramakrishnan R (2010) Investigation of the outbreak of typhoid in a village of Thar Desert Rajasthan, India. Indian Journal of Medical Research 131: 799-803.

9. Mbakaya BC, Mukora Mutseyekwa F, Chideme Munodawafa A, Mwale CM, Mnyenyembe LM, et al. (2015) Factors associated with development of typhoid fever at Kaziwiziwi coal mining area in Rumphi District, Malawi: A retrospective case control study. European Scientific J 1111(3333): 1857-7881.

10. Talaat M, Afifi S, Dueger E, El Ashry N, Marfin A, et al. (2011) Effects of hand hygiene campaigns on incidence of laboratory-confirmed influenza and absenteeism in schoolchildren, Cairo, Egypt. Emerging Infectious Diseases J 17(4): 619-625.

11. Patel MK, Harris JR, Juliao P, Nygren B, Were V, et al. (2012) Impact of a hygiene curriculum and the installation of simple handwashing and drinking water stations in rural Kenyan primary schools on student health and hygiene practices. American J Tropical Med Hygiene 87(4): 594-601.

12. (2012) Typhoid Fever Outbreak Report. Rumphi District Health Office.

13. Kaewchana S, Simmerman M, Somrongthong R, Suntarattiwong P, Lertmaharit S, et al. (2012) Effect of intensive handwashing education on handwashing behaviours in Thai households with an influenzapositive child in urban Thailand. Asia Pac J Public Health 24(4): 577-585.

14. Rosen L, Manor O, Engelhard D, Brody D, Rosen B, et al. (2006) Can a handwashing intervention make a difference? Results from a randomized controlled trial in Jerusalem preschools. Preventive Medicine 42(1): 2732.

15. Saboori SLEG, Moe CL, Freeman MC, Caruso BA, Akoko D, et al. (2013) Impact of regular soap provision to primary schools on handwashing and E. coli hand contamination among pupils in Nyanza Province, Kenya: A Cluster-Randomised Trial. Am J Trop Med Hyg 2013;89(4):698-708.

16.Zhang C, Mosa AJ, Hayward AS, Mathews SA (2013) Promoting clean hands among children in Uganda: A school-based intervention using 'tippy-taps'. Public Health 127(6): 586-589.

17. (2016) Centers for Disease Control and Prevention. When \& How to Wash Your Hands USA: Centers for Disease Control and Prevention.

18. (2015) United Nations Children's Fund. Advancing WASH in School Monitoring. In: WASH, editor. New York, NY 10017 USA: UNICEF.

19. Bandura A (1977) Social learning theory. New York: Prentice-Hall Englewood Cliffe. 


\section{ISSN: 2574-1241}

DOI: 10.26717/BJSTR.2019.16.002908

Balwani Chingatichifwe Mbakaya. Biomed J Sci \& Tech Res

(C) (P) This work is licensed under Creative

Submission Link: https://biomedres.us/submit-manuscript.php

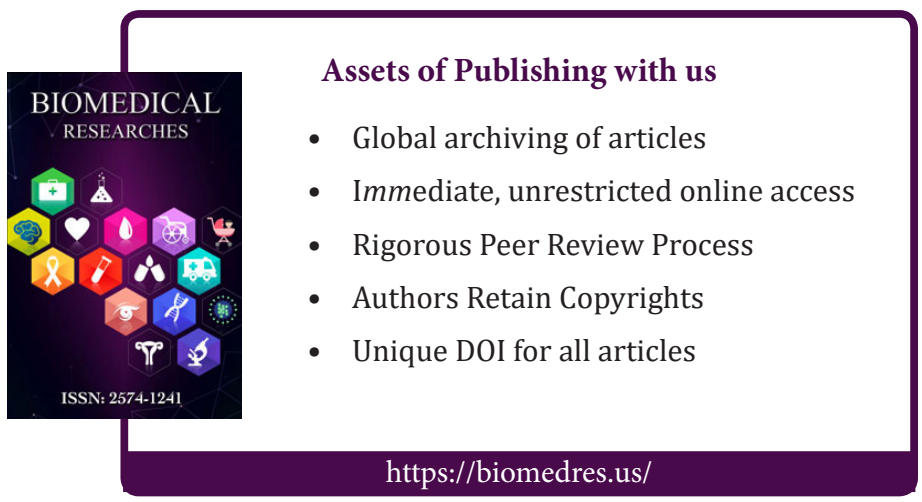

